\title{
Investigating Possible Evolutionary Reduction in Subject Nominal Group Complexity in Prose Fiction Text
}

\author{
Yaser Hadidi (Corresponding Author) \\ Dept. of English, The University of Tabriz, Tabriz, Iran \\ E-mail: hadidiy@yahoo.com \\ Sepideh Ghandkaran-Shotorban \\ Dept. of English, The University of Tabriz, Tabriz, Iran \\ E-mail: sepideh.ghandkaran@gmail.com
}

Received: January 19, 2015 Accepted: January 30, 2015 Published: February 2, 2015

doi:10.5296/jsel.v3i1.7038 URL: http://dx.doi.org/10.5296/jsel.v3i1.7038

\begin{abstract}
In this paper, an attempt is made to put to text analytic and stylistic test Norman Blake's hypothesis (Blake, 1990) that the system of clause in literature-text has evolved from the eighteenth century all the way into the late twentieth in terms of noun groups becoming less complex and elaborate. A corpus of novels is selected such that every time span of fifty years can be represented by at least two novels. Then, in order to study the noun groups of respective evolutionary periods in question, it is the noun group in subject position that is subjected to analysis in terms of complexity, the key term of this stylistic study, which is taken to be analyzable through two yardsticks: a) the straightforward lexical density, i.e. the number of words inside the subject, and b) how many instances of 'embedding' there are in that nominal functioning as subject. The study could not find support for Blake's initial hypothesis as to the downward evolutionary trend in the complexity of noun groups, yet it brings out other implications and functions attributed to noun groups in subjecthood, over these respective historical periods, as used by novelists thereof.
\end{abstract}

Keywords: Complexity, Noun Group, Stylistics, Lexical Density, Embedding 


\section{Introduction}

Literature-text, in its different manifestations, is worthy of consideration on different levels. These are looked at in different ways and with different results; and it is the different 'layers' of description and analysis that determines the outcome and the insight accruing from the research-oriented undertaking. What is crucial is putting down in explicit terms the vantage-point of analysis, the layer from which one starts and hopes to draw conclusions, the unit and the demarcation of the analysis. This enters into natural synergy with the size and boundaries of the claims and hypotheses of the research, with how modest and realistic they are, and not any less so, with if and how the results accord themselves closely enough with the initial claims at the end of the day.

If the study makes certain discursive claims of certain patterns of thought and speech presentation, for instance, then the findings should bring out conclusions in line with such claims and not more. There might be less, yes, in the sense that certain assumptions and expectations are not met at the end, but it's always too unguarded and precarious to go even slightly beyond one's demarcated remit. A study might make critical/discursive claims, that, for example, certain ideological planes and packages are being conveyed in a piece of literary discourse. It is now common knowledge in linguistic stylistic circles that the number of notches on this continuum and the upper limit on the inclusiveness of analysis in literature-text are not only unknown, but, more importantly, rather impossible and pointless to define. Perhaps this is all for the better; curiously and interestingly enough, this feeds back into our reminder above that every study needs to state in very clear terms its claims, scope, size, and hopes.

In the same spirit, let this study clarify at the outset that it sets out to make certain generalizations for the genre of English fictional prose at the level of the 'sentence' and only the noun clause in subject position at that.

\subsection{Objectives and Significance}

A distinctive cornerstone of the text of fiction, especially if one were to look at the level of the sentence and its specific use in such text, is the more complex structure of the nominal groups relative to the nominal groups in other genres. It seems that part of the processing difficulty, for those new to the genre anyway, stems from the cognitive burden the noun groups place on the reader, particularly the so-called 'multi-embedded' nature of these noun groups in English fiction. Furthermore, Blake's (1990) hypothesis that the noun phrase in the novel chronologically drops in complexity was never put to text analytic test. This study subjects to analysis the nominal groups in eight novels, every two of which represent a time span of fifty years starting from 1800. The objective is to see if the hypothesis that in the English novel there is a downward chronological reduction along the two dimensions of complexity and lexical density in the subject-position noun phrase proves a sound one upon analysis or not. So there are two pursuits involved:

1) As Blake (1990) hypothetically claimed, has complexity dropped chronologically for the noun groups in subject position in the genre of the English novel? 
2) As Blake (1990) hypothetically claimed, has lexical density dropped chronologically for the noun groups in subject position in the genre of the English novel?

Here, we do not align ourselves with the definition of lexical density proposed, for example, by Halliday and Matthiessen (2004) which advises to measure lexical density through dividing the number of lexical items by the number of ranking clauses. Here, we think it is more interesting to know the bare 'word count' of subject nominals as they evolve through the years. It is a rather automatic result of high lexical density that the word count of such noun phrases will also be high and vice versa. That notion of lexical density was used by Halliday to talk about the differences between written and spoken language anyway. For our current purposes, of chief concern is to look into the fact that the mere and simple 'word count' of the noun phrase in subject position has also decreased.

\section{Theoretical Background}

Stylistics, as a branch of Applied Linguistics, is concerned with the study of style. Although this concept is widely known and used, it is difficult to define and has many different nuances and angles from which to conceptualize it. What is certain, however, is that its essence is 'distinction', 'variation', or 'choice'. Therefore, stylistics can be defined as the analysis of distinctive expression in language, whether at the level of phonology, grammar, lexis, semantics, or discourse (Verdonk, 2002; Wales, 2006). Widdowson (1975) quite rightly shows that "stylistics can provide a way of mediating between two subjects of English language and literature" (p. 4). From a practical point of view, an entryway is necessary to put any piece of literary text to stylistic analysis.

Blake (1990) believes that syntax is the best place to start the analysis with mostly because exposing the structure of a text leads straight to its heart. In this regard, he categorizes three ways of approaching the structure: "the clause elements which go to make up each sentence; the presentation of the content in theme/rheme and topic/comment formats; and the wider organization of each sentence into declarative, interrogative or imperative patterns" (p. 11). He claims each sentence consists of clause elements, of which in English there are five. They are subject, predicator, object, complement, and adjunct. Each of these elements can be represented by a group of words, such as noun group, adjective group, verb group, adverb group, or prepositional group.

Of these, the noun group is perhaps the most important because of its make-up and role. Blake claims that a noun group consists of up to five elements: pre-determiner, determiner, modifier, head, and qualifier (also called post-modifier). It is crucial to mention here that the order of elements is important. This, however, does not mean that the presence of all the elements is needed to name a group of words a nominal group. Simply stated, one element cannot precede another. While Blake (1990) differentiates five elements, other scholars like Wright and Hope (1996) merge pre-determiner and determiner, thereby identifying the structure of a noun group in terms of four predetermined slots that are: determiner (enumerator), pre-head modification, head noun, and post-head modification.

As Blake (1990) goes on to bring out, only one of the aforementioned elements, the head, is 
obligatory. And all the others are optional. A brief explanation of each element will be in order here. Pre-determiners, as the name suggests, precede determiners. The words indicating quantity such as all and half can act as pre-determiners. Determiners belong to a closed class of words which are in traditional grammar classified as articles, possessive adjectives, demonstrative adjectives, or interrogative adjectives. It is also interesting to know that they are mutually incompatible, that is, you cannot have two words in the same class following each other. Modifiers, on the other hand, belong to an open class of words.

Wright and Hope (1996) show that modifiers are single words which are either adjectives or nouns with adjectival functions. In contrast, Blake (1990) accentuates the fact that some modifiers may be preceded by intensifiers such as very. This, he believes, is one of the few instances in which a modifier consists of more than a single word. Qualifiers or post-modifiers are the units, mostly in Hallidayan perspective a phrase or a clause, which follow the head in a nominal group (e.g. Halliday, 1985).

The notion of qualifiers is highly related to embedding. According to Halliday (1985), all qualifiers, excluding some rare exceptions, are embedded. Halliday provides the following definition of embedding:

..... position following the Thing [head of the nominal group] is reserved for those items which, in their own structure, are of a rank higher than or at least equivalent to that of the nominal group; on these grounds, therefore, they would not be expected to be constituents of a nominal group. Such constituents are said to be 'embedded', or, in earlier systemic terms, 'rankshifted'. (p.166)

Blake (1990) distinguishes different types of qualifiers, the most common types of which are prepositional phrases, relative clauses, appositions, and the adjectives used after the noun.

A final point to be made, in Blake's terms, is that the nominal groups in most forms of literary writing carry the bulk of the linguistic embellishment. This is so because among other units of language, it is the noun group that can be expanded and adapted most. In this respect, the modifying and post-modifying elements are used to add to the heaviness of noun groups.

In this study, this is what we intend to dwell on, i.e. the heaviness or 'embedded-ness' of the noun group as subject and the evolutionary character found in the historical journey of the style of the English novel from the eighteenth century down to the twentieth in terms of the gradual downward reduction in embedded-ness of the nominal acting as subject.

\section{Method}

\subsection{Corpus}

Eight novels were randomly selected from the pool of famous, and, therefore representative, novels of English literature in a way that each time period in $19^{\text {th }}$ and $20^{\text {th }}$ centuries (i.e. 1800-1850, 1850-1900, 1900-1950, and 1950-2000) was represented by two novels. The list is shown below:

- $\quad$ Pride and Prejudice by Jane Austen (1999) 
- Dombey and Son by Charles Dickens (2001)

- Great Expectations by Charles Dickens (2010)

- Tess of the d'Urberville by Thomas Hardy (2014)

- A Portrait of the Artist as a Young Man by James Joyce (2005)

- Mrs. Dalloway by Virginia Woolf (2014)

- Lord of the Flies by William Golding (2014)

- Gravity's Rainbow by Thomas Pynchon (2010)

\subsection{Procedures}

Once adequate groundwork was laid down for the purposes of textual analysis and data collection, every tenth page of each novel was randomly subjected to analysis using Blake's (1990) noun-group-structure framework. To make the data comparable, the number of analyzed noun groups in subject position in all novels was equal with that of the shortest novel. Then the mean of embedding was calculated for each novel and later for each time period. In order to calculate lexical density, the number of words in each noun group was counted and then averaged. The sample nominal subjects listed and analyzed briefly below obviously do not contain the main verb and only contain all the components inside the nominal element acting as subject.

\section{Results and Findings}

Table 1 below sums up the main information in the analysis of lexical density and embedding in each novel. Table 2 goes on to put rather the same information in something of an informative nutshell by presenting the overall means of lexical density and embedding in each time period in question. Let us take up each time period in turn and look more closely at the subject noun phrases in the novels therein before we comment on the findings conveyed by the tables.

Table 1 . The means of lexical density and embedding in each novel

\begin{tabular}{|c|c|c|c|}
\hline $\begin{array}{c}\text { Time } \\
\text { Periods }\end{array}$ & $\begin{array}{c}\text { Novels with their Original Years of Publication in } \\
\text { Each Time Period }\end{array}$ & $\begin{array}{c}\text { Lexical } \\
\text { Density }\end{array}$ & Embedding \\
\hline \multirow{2}{*}{$1800-1850$} & Pride and Prejudice (1813) & 8.54 & 1.68 \\
\cline { 2 - 4 } & Dombey and Son (1848) & 12.24 & 2.10 \\
\hline \multirow{2}{*}{$1850-1900$} & Great Expectations (1860) & 9.34 & 1.78 \\
\cline { 2 - 4 } & Tess of the d'Urberville (1891) & 9.57 & 1.98 \\
\hline
\end{tabular}




\begin{tabular}{|c|c|c|c|}
\hline \multirow{2}{*}{$1900-1950$} & A Portrait of the Artist as a Young Man (1916) & 8.08 & 1.88 \\
\cline { 2 - 4 } & Mrs. Dalloway (1925) & 7 & 1.68 \\
\hline \multirow{2}{*}{$1950-2000$} & Lord of the Flies (1954) & 6 & 1.35 \\
\cline { 2 - 4 } & Gravity's Rainbow (1973) & 6.55 & 1.66 \\
\hline
\end{tabular}

Table 2. The overall means of lexical density and embedding in each time period

\begin{tabular}{|c|c|c|}
\hline Time Periods & Lexical Density & Embedding \\
\hline $1800-1850$ & 10.39 & 1.89 \\
\hline $1850-1900$ & 9.45 & 1.88 \\
\hline $1900-1950$ & 7.54 & 1.78 \\
\hline $1950-2000$ & 6.27 & 1.50 \\
\hline
\end{tabular}

4.1 1800-1850: Pride and Prejudice by Jane Austen (1999); Dombey and Son by Charles Dickens (2001)

Examples of noun phrases in subject position, especially those involving embedding, from the novel Pride and Prejudice are listed below. The head nouns, when applicable (when we are not dealing with nominal subjects like the first one below which uses the choice in English grammar between starting a noun phrase with either the fact that or that, interchangeably), are underlined.

1) That she should have walked three miles so early in the day, in such dirty weather, and by herself

2) Jane, who had only been withheld by the fear of giving alarm or inconvenience, from expressing in her note how much she longed for such a visit

3) A thorough, determined dislike of me, a dislike I cannot but attribute in some measure to jealousy

4) The respect which he felt for her high rank, and his veneration for her as his patroness, mingling with a very good opinion of himself, of his authority as a clergyman, and his rights as a rector

5) The vague and unsettled suspicions which uncertainty had produced of what Mr. Darcy might have been doing to forward her sister's match, which she had feared to 
encourage, as an exertion of goodness too great to be probable, and at the same time dreaded to be just, from the pain of the obligation

The novel does, of course, use shorter and less embedded subjects too, but we can see the main body of strategies used for embedding in these examples. In the first example, embedding is achieved by one single noun clause starting with that and a prepositional and adverbial phrase in dirty weather and by herself embedded inside it.

In the second one, there is a relative (adjective) clause modifying the head noun Jane, and there are two prepositional phrases embedded under it starting with by the fear of and from expressing. The third one uses appositive construction for embedding (for the head noun dislike) and, again, adjective clauses embedded inside it.

The fourth example involves two subjects coordinated with and and the two head nouns respect and veneration; coordination cannot count as embedding because it does not involve a relation of dependency. But both subjects will delay the reader's processing and comprehension before they reach the verb. Both use prepositional post-modifying elements with for and noun phrases embedded inside it. But the first one brings an adjective clause starting with which to modify the head noun respect. The second one employs prepositional phrase as post-modification and a non-finite adverbial mingling and, inside it, again three parallel prepositional phrases using of, thus achieving a high level of embedding overall for the whole noun phrase subject. In the last example, again, there are quite a few adjective clauses post-modifying the head noun suspicions, embedded one inside the other.

Let us look at examples from Dombey and Son and see if roughly similar strategies for embedding have been used:

1) Mr. Dombey dismounting first to help the ladies out, and standing near him at the coach door

2) The name of this retirement, where grass grew between the chinks in the stone pavement

3) One young gentleman, with a swollen nose and an exceedingly large head

4) His quick transition to a state of unbounded pleasure, as he stood at his window, kissing and clapping his hands, and the way in which the light retreated from his features as she passed out of his view, and left a patient melancholy on the little face

5) The Captain being at length attired to his own complete satisfaction, and having glanced at himself from head to foot in a shaving-glass which he removed from a nail for that purpose

The first nominal subject uses two non-finite clauses as post-modification. The second uses an adjective clause starting with where and an adverb of place realized as a prepositional phrase. The third example of subject noun phrases uses two parallel and coordinated prepositional phrases as post-modification. The fourth is, in fact, two coordinated subjects in a row before we reach the main verb, the first of which is followed by one prepositional 
phrase, one adverbial clause, and two non-finite elements as post-modification, and the second of which uses way as head noun in the way in which and heavily embedded elements following it modifying the embedded non-head noun the light. The last example uses non-finite clauses and embedded elements inside them in turn.

This small-scale analysis of the sentential makeup of the nominal subjects in two rather separate and random novels of the same historical era reveals, first of all, that a case could be made for a roughly similar body of embedding strategies used by writers to come up with long, embellished, and dense subjects in their writing.

4.2 1850-1900: Great Expectations by Charles Dickens (2010); Tess of the d'Urberville by Thomas Hardy (2014)

Examples for these two novels chosen from the era spanning 1850 to 1900 are as follows. The first set belongs to Great Expectations.

1) Mr. Wopsle, united to a Roman nose and a large shining bald forehead

2) The strange gentleman, with an air of authority not to be disputed, and with a manner expressive of knowing something secret about every one of us that would effectually do for each individual if he chose to disclose it

3) The suitor, kissing the hem of the garment again before relinquishing it

4) Bentley Drummle, who was so sulky a fellow that he even took up a book as if its writer had done him an injury

5) The murdered person-more a match for the man, certainly, in point of years-

Here again we have the same embedding strategies at work: non-finite participial elements in the first, prepositional post-modification with heavily embedded adjective clauses and post-modifying elements inside it in the second, non-finite post-modification in the third, embedded relative (adjective) clause in the fourth, and appositive adverbial in the fifth. Now some examples from Tess of the d'Urberville:

1) Durbeyfield, leaning back, and with his eyes closed luxuriously

2) The d'Urbervilles- or Stoke-d'Urbervilles, as they at first called themselves- who owned all this

3) The male milkers, with hat-brims turned down, resting flat on their foreheads and gazing on the ground

4) The full recognition of the futility of their infatuation, from $a$ social point of view; its purposeless beginning; its self - bounded outlook; its lack of everything to justify its existence in the eye of civilization (while lacking nothing in the eye of Nature); the one fact that it did exist, ecstasizing them to a killing joy 
5) The night which had already swallowed up his happiness, and was now digesting it listlessly; and was ready to swallow up the happiness of a thousand other people with as little disturbance or change of mien

The first noun phrase uses a non-finite and a prepositional phrase at the same time. The second uses appositive, adverbial, and adjective clauses for the head noun. The third employs a prepositional phrase and two embedded non-finite clauses following it. The fourth draws upon several noun phrases in a row, accompanied by embedding in the form of prepositional phrases, non-finite elements following the head noun lack, and a noun clause post-modifying the head noun fact along with the non-finite ecstasizing. And the last one mounts heavy embedding for the head noun night using adjective clauses and other non-finite and prepositional elements embedded inside them.

We can see that the same set of strategies of embedding in the subject noun phrase used in the prose fiction of the years spanning 1800-1850 are rather similarly used in the era of 1850-1900.

4.3 1900-1950: A Portrait of the Artist as a Young Man by James Joyce (2005); Mrs. Dalloway by Virginia Woolf (2014)

Here are examples from A Portrait of the Artist as a Young Man follow:

1) Uncle Charles, who sat far away in the shadow of the window, Dante and Mr. Casey, who sat in the easy chairs at either side of the hearth, Stephen, seated on a chair between them, his feet resting on the toasted boss

2) Death and Judgment, brought into the world by the sin of our first parents

3) The voices that he knew so well; the common words, the quiet of the classroom when the voices paused and the silence was filled by the sound of softly browsing cattle as the other boys munched their lunches

4) The spiritual triumph which he felt in achieving with ease so many fabulous ages of canonical penances

5) Their diving stone, poised on its rude supports and rocking their plunges, and the roughhewn stones of the sloping breakwater over which they scrambled in their horseplay

Here in the first novel chosen from the first half of the twentieth century, we have the same patterns and strategies in the embedding of subject noun phrases. In the first example, we can see adjective clauses post-modifying the head nouns. In the second, there is a participial non-finite for two coordinated head nouns. In the third, the head nouns are modified by a dependent clause of when that, in turn, has other adverbial elements embedded inside it. In the fourth, modifying the head noun triumph is one adjective clause of which with prepositional phrases and objects of non-finite verbs embedded inside it. In the last one, the head noun stone is again modified by two non-finite participles (one present, the other past), and the head noun stones post-modified by of and the adjective clause over which. 
The following lists sample nominal groups from Mrs. Dalloway:

1) The white busts and the little tables in the background covered with copies of the Tatler and siphons of soda water

2) Little Mr. Bowley, who had rooms in the Albany and was sealed with wax over the deeper sources of life but could be unsealed suddenly, inappropriately, sentimentally, by this sort of thing - poor women waiting to see the Queen go past - poor women, nice little children, orphans, widows, the War -

3) A breeze flaunting ever so warmly down the Mall through the thin trees

4) The swish of a mop; tapping; knocking; a loudness when the front door opened; a voice repeating a message in the basement; the chink of silver on a tray; clean silver for the party

5) And the doctors and men of business and capable women all going about their business, punctual, alert, robust

Here, similar patterns of embedding exist for nominal groups. The first example with two head nouns is qualified (post-modified) by a prepositional phrase and a non-finite. The second one is qualified by a very complex adjective clause starting with who. The complexity, as a matter of course, is due to heavy and multi-layered embeddedness. The third is qualified by a non-finite and a number of prepositional phrases embedded in it. The fourth one evidences several head nouns in an appositive relationship. Loudness is accompanied by a dependent clause, voice is qualified by a non-finite, chink by a prepositional phrase. The last one has three head nouns qualified by a non-finite and adjectival complements as adverbial.

4.4 1950-1973: Lord of the Flies by William Golding (2014); Gravity's Rainbow by Thomas Pynchon (2010)

The last span of fifty years considered here is the years 1950-2000. The first work of fiction selected to represent this era is Lord of the Flies, of which sample nominal groups in subject position are presented below:

1) Those who were aware that ship had passed the island while the fire was out

2) Maurice, who had been standing ready to dive

3) The densest tangle on the island, mass of twisted stems, black and green and impenetrable

4) The bottom part of the trickle, as though conscious of their gaze

5) The flame, nearly invisible at first in that bright sunlight

Example 1 uses an adjective clause and an embedding noun clause inside it. Example 2 uses a defining relative clause again. Example 3 uses an appositive and post-modifying adjectives. Example 4 has a reduced adjective clause post-modifying it, as does Example 5. Below are subject nominal groups from Gravity's Rainbow: 
1) The road, which ought to be opening out into a broader highway,

2) Jessica Swanlake, a young rosy girl in the uniform of an ATS private, noticing the prewar perfume,

3) The act of ramming home the charges into their musketry

4) Clouds, some in very clear profile, black and jagged,

5) The dossier that Tchitcherine put together on Enzian

Here, the first subject nominal group uses a defining relative clause; the second an appositive phrase and a non-finite following it; the third a prepositional phrase and embedded object noun phrase inside the embedded verb; the fourth a reduced adjective clause post-modifying the head noun. The last one uses a non-defining relative clause.

\section{Discussion: Multi-embedded subjects in English Fiction}

Tables 1 and 2 indicate that as we go further back in the history of the novel, there may be evidence that subject nominal groups are longer in sheer size (and word count), but, at least in this study, support could not be provided for the notion of differences in embedding and more complexity in older eras of prose fiction in English literature. Speaking based on the data, one should perhaps look elsewhere for the origins and factors involved in higher processing difficulty of $18^{\text {th }}$ - and $-19^{\text {th }}$ - century texts of prose fiction claimed by many students to lie in the more embedded nature of nominal groups and their multi-embedded complexity. What is known, and is attested by the data here, is that the 'textual devices' and 'strategies' used by prose writers as far apart as two centuries seem to constitute a common intertextual pool of resources that writers, consciously or unconsciously, draw upon to add and embed the necessary information and details into their nominal groups (modify them using different types of modification for the noun going hand in hand with embedding).

\section{Conclusion, Comments and Suggestions}

Strictly speaking, in order to probe stylistic differences in the structure of the sentence in different eras and types of prose fiction, further research can be undertaken. We think one particular area that is the domain of genre-specific properties in prose fiction text is adverbials and adverbial elements.

In addition, if, as in this study, embedding and lexical density are not very different across different eras, there could be quests that set out to answer why advanced students constantly voice the complaint that the English prose fiction penned in $18^{\text {th }}$ and $19^{\text {th }}$ presents them with a lot of syntactic and grammatical difficulty, not just lexical. Therefore, there should be more research in this regard that brings into the equation frameworks from psycholinguistics, theories of narrative comprehension, participants, and assessments to look at the other side of the matter, i.e. the comprehension of different texts of fiction by readers.

It is obvious here that there is only a certain size of textual material that can be investigated in the scope of one paper; other and more novels could, therefore, be analyzed for differences in complexity, embedding, lexical density, and other stylistic properties. Moreover, further 
research could look at many other possibilities, like looking at differences in embedding between fiction and non-fiction.

\section{References}

Austen, J. (1999). Pride and prejudice. London: Wordsworth Editions Limited.

Blake, N. F. (1990). An introduction to the language of literature. London: Macmillan.

Dickens, Ch. (2001). Dombey and son. Oxford: Oxford University Press.

Dickens, Ch. (2010). Great expectation. London: Harper Press.

Golding, W. (2014). Lord of the flies. DOI: gv.pl/pdf/lord_of_the_flies.pdf

Halliday, M. A. K. (1985). An introduction to functional grammar. London: Edward Arnold.

Halliday, M. A. K. \& Matthiessen, C. M. I. M. (2004). An introduction to functional grammar ( $3^{\text {rd }}$ ed.). London: Arnold.

Hardy, Th. (2014). Tess of the d'urberville. Retrieved from http://www.planetebook.com/ebooks/Tess-of-the-dUrbervilles.pdf (May 5, 2014)

Joyce, J. (2005). A portrait of the artist as a young man. New York: Bantam Dell.

Pynchon, Th. (2010). Gravity's rainbow. Retrieved from http://en.bookfi.org/s/?q=Gravity\%27s+rainbow\&t=0 (February 2, 2012)

Verdonk, P. (2002). Stylistics. Oxford: Oxford University Press.

Wales, K. (2006). Stylistics. In J. L. Mey (Ed.), Concise encyclopedia of pragmatics. (pp. 1046 1051). Denmark: University of Southern Denmark.

Widdowson, H. G. (1975). Stylistics and the teaching of literature. England: Longman.

Woolf, V. (2014). Mrs. dalloway. Retrieved from https://ebooks.adelaide.edu.au/w/woolf/virginia/w91md/ (May 2, 2014)

Wright, L. \& Hope, J. (1996). Stylistics: a practical coursebook. London: Routledge.

\section{Copyright Disclaimer}

Copyright for this article is retained by the author(s), with first publication rights granted to the journal.

This is an open-access article distributed under the terms and conditions of the Creative Commons Attribution license (http://creativecommons.org/licenses/by/3.0/). 